\title{
Os programas brasileiros em eficiência energética como agentes de reposicionamento do setor elétrico
}

The Brazilian energy efficiency programs as agents of repositioning in the electricity sector

\author{
Andréa de Souza \\ Jorge Carlos Correa Guerra \\ Eduardo Leite Kruger
}

\section{Resumo}

As iniciativas em eficiência energética dos países desenvolvidos foram importantes referências para o desenho de programas similares que surgiram no Brasil nos anos de 1980, em decorrência da crise de suprimentos de energéticos. O presente artigo propõe resgatar introdução da conservação e eficiência energética na agenda de discussão do setor elétrico brasileiro, os principais programas e marcos regulatórios e um panorama sintético sobre os resultados do PROCEL em 2009. A metodologia empregada foi revisão da literatura e consulta a documentos oficias.

Palavras-chave: Eficiência Energética, Programas Nacionais, PROCEL.

\begin{abstract}
The energy efficiency initiatives in the developed countries were important references for the similar programs design that emerged in Brazil in 1980, due to the crisis of energy supplies. This Article proposes to rescue the brasilian introduction of the conservation and energy efficiency in its discussion agenda of the electricity sector, major programs and regulatory frameworks and an overview on the results of PROCEL in 2009. The methodology employed was a literature review and consultation with official documents.
\end{abstract}

Keywords: Energy Efficiency, National Programs, PROCEL.

\section{Introdução}

Diante da surpresa frente aos choques do petróleo que geraram as crises de suprimento de energia, dirigentes das grandes economias mundiais readequaram suas estratégias de administração e uso dos energéticos. O presente artigo se propõe a tratar do tema conservação e eficiência energética a partir das iniciativas para minimizar os problemas das crises de abastecimento. A primeira seção trata de um histórico dos programas de eficiência energética no mundo e como a temática entrou na agenda do país, a segunda o resgate histórico dos principais programas brasileiros, considerações gerais sobre eficiência energética no Brasil e resultados do ciclo 2009 divulgados pelo PROCEL.

\section{Eficiência Energética no Mundo e o Brasil}

A eficiência energética passou a preocupação mundial a partir da primeira crise do petróleo, na década de 1970. Os países industrializados organizaram-se e fundos foram levantados para investimentos em projetos de eficiência energética e fontes renováveis de energia, cujo objetivo era diminuir a dependência em relação ao petróleo e derivados.

Em meados dos anos de 1980, o impacto da queima de combustíveis fósseis na variação climática global entrou na pauta de discussões em todo mundo. Resultado destas inquietações foi o Protocolo de Kyoto em 1997, acordo internacional em que os países signatários estabeleceram metas de redução de emissões de $\mathrm{CO}_{2}$ (HADDAD, 2006). Para atingir aos objetivos propostos pelo protocolo, tornou-se imperativa a criação de mecanismos que estimulassem a eficiência em toda a cadeia energética.

a) Reino Unido: o plano governamental focou na conscientização da população e no gerenciamento de programas do Departamento de Meio Ambiente, Transportes e Regiões (DETR) e do programa Electricity Standart of Performance (SoP). Foram implementados modernos aquecedores de água, controle de aquecimento, melhorias no isolamento de paredes na construção 
civil, utilização de combustíveis alternativos, educação, iluminação eficiente e fomento a empreendimentos que contribuíssem com a conservação de energia (DEFRA, 2004).

b) França: as atividades em eficiência energética são de responsabilidade da Agência do Meio Ambiente e da Matriz Energética (ADEME) com interação entre políticas ambientais e energéticas. As áreas prioritárias foram a economia dos resíduos, poluição do ar e matriz energética limpa. (ADEME, 2006).

c) Espanha: a promoção da eficiência energética no país dá-se por meio do Instituto para a Diversificação e Economia Energética (IDAE), entidade pública empresarial. Desenvolve projetos de fomento ao uso racional da energia e incentivo às fontes renováveis, auditorias energéticas, estímulo ao uso de combustíveis limpos e substituição de equipamentos obsoletos (IDAE, 2006).

d) Canadá: iniciou seus programas de eficiência energética na década de 1970. Em 1995 foi criado o National Action Program on Climate. Os principais programas são voltados à indústria, setor público, transportes, normalização de equipamentos na construção civil, programa de etiquetagem de equipamentos eficientes e orientação de consumidores; estímulo à construção e às reformas dentro de padrões eficientes e de conservação de energia (CLIMATE CHANGE, 2006).

e) Estados Unidos: o Departamento de Energia Americano (DoE) atua por meio do Energy Efficiency and Renewable Energy Network (EERN). Objetiva estimular a exploração de fontes renováveis e a competitividade econômica como forma de baixar custos e proteger o meio ambiente. O foco são as empresas concessionárias de energia, a indústria e os setores de transporte e da construção civil (EERE, 2007). O DoE investe na pesquisa e desenvolvimento além da aplicação de mecanismos de mercado como os Programas de Etiquetagem e Padronização de Equipamentos (DoE/EPA).

f) Outros países: Japão, Noruega, Dinamarca, Suécia, Nova Zelândia e Austrália desenvolvem programas similares buscando reduzir desperdícios de energia em todos os segmentos de consumo, por meio de mecanismos similares especialmente com a adoção de programas de etiquetagem e a normalização de produtos, métodos e processos industriais. (STRAPASSON, 2004).

Os principais eventos que deram início às discussões em torno da conservação e energética data da década de 1970 e são uma resposta à crise do petróleo (EPE, 2007):

- $1973 \quad 1^{\circ}$ Choque do Petróleo;

- 19751 ํ Seminário sobre o tema conservação de energia (MME);

- 1979 2 Choque do Petróleo;

- 1982 Programa de Mobilização Energética.

A estratégia adotada como política de oferta de energia contemplou as ações de intensificação da prospecção de petróleo, incremento da produção de carvão, lançamento de um programa nuclear com vistas à transferência de tecnologia e a construção de usinas nucleares para a geração de energia elétrica, criação do Programa Nacional do Álcool (PROÁLCOOL) e no setor elétrico foi dado continuidade à expansão da base hídrica para geração de eletricidade.

Neste sentido, o governo brasileiro passou a focalizar a questão do óleo combustível consumido na indústria com aumentos de preços a partir de 1980, além de um corte de $10 \%$ e $5 \%$, respectivamente, e implantação de um sistema de controle de abastecimento por meio de cotas de combustíveis até o ano de 1983. (MARTINS et.al., 1999). As medidas foram mal recebidas pelos empresários, e no ano de 1981 o governo lançou o programa CONSERVE que "constitui a principal experiência de fomento a eficiência energética no Brasil" (PICCINI, 1994 p.154).

Durante a década de 1980 novos problemas ganharam visibilidade política. Martins et al. (1999) destacam a crescente utilização da eletricidade para fins térmicos no setor industrial, fomentada parte pelo CONSERVE e pelo programa de Eletro-termia resultando em pressões sob a capacidade de oferta do setor que já estava passando por uma crise financeira. Além disso, tornaram-se crescentes as preocupações com o meio ambiente e questionamentos relativos ao desperdício de energia. Sobre esse período destacam-se os seguintes eventos:

- 1984 Programa Brasileiro de Etiquetagem (PBE);

- 1985 Programa Nacional de Conservação de Energia Elétrica (PROCEL);

- 1991 Programa Nacional de Conservação de Petróleo e Derivados (CONPET);

- 2001 Lei no 10295 Política Nacional de Conservação e Uso Racional de Energia.

A partir de 1998, obrigatoriedade de investimentos em programas de conservação pelas concessionárias, sob fiscalização da Agência Nacional de Energia Elétrica (ANEEL), ratificado pela Lei no 9.991/2000 e alterações subseqüentes. No ano de 2001, durante o racionamento de energia elétrica, diversas medidas de incentivo foram estimuladas, com destaque para a Lei no 10.295, que dispõe sobre a Política Nacional de Conservação e Uso Racional de Energia (GUERREIRO, 2006). 


\title{
Principais Programas Nacionais de Conservação de Energia no Brasil
}

\author{
Programa CONSERVE
}

O Programa CONSERVE foi criado no âmbito do Ministério da Indústria e Comércio (MIC), em 1981. Constituiu-se num esforço de peso em conservação de energia no Brasil, cujo objetivo era atender as exigências da Portaria MIC/GM46, que referenciava a promoção da conservação de energia na indústria - desenvolvimento de produtos e processos energeticamente eficientes e ao estímulo à substituição de energéticos importados por fontes alternativas internas. Este programa foi responsável por uma queda em torno de $18 \%$ no consumo industrial de óleo combustível já no ano de seu lançamento.

Distorções ocorridas no CONSERVE e obstáculos como a crise econômica da década de 1980 impediram que se atingisse o potencial pleno de ação previsto inicialmente. No ano de 1981, a recessão econômica resultou em ociosidade da capacidade instalada do parque gerador de energia elétrica, enquanto ênfase era dada à necessidade de diminuição do consumo de derivados de petróleo por parte da indústria face à elevação dos preços no mercado internacional. Nesse contexto,foi criada a Energia Garantida por Tempo Determinado (EGTD), que tinha como alvo o setor industrial então pressionado pelos altos preços dos derivados de petróleo (MARTINS et al., 1999).

A despeito dos resultados satisfatórios, o CONSERVE foi indiretamente responsável pelo processo de transferência da responsabilidade da conservação de energia para o setor elétrico, dado o crescimento da demanda por energia elétrica para fins térmicos do setor industrial. A política de tarifas de energia elétrica dos anos 1980, num cenário de descontrole inflacionário e a inviabilidade de financiamento da expansão do setor elétrico, resultaram na única estratégia possível que foi o governo partir para a implementação de políticas de conservação do uso da energia elétrica.

\section{Programa Nacional de Conservação de Energia Elétrica}

A Portaria Interministerial oㅜ 1.877, 10/12/85, foi instituída por iniciativa conjunta do MME e do MIC, com o objetivo de criar o Programa de Combate ao Desperdício de Energia Elétrica (PROCEL). O principal desígnio do programa era "[...] maximizar seus resultados e promover um amplo espectro de novas iniciativas, avaliadas à luz de um rigoroso teste de oportunidade, prioridade e economicidade" (MARTINS et al., 1999, p.48).

Em 18 de julho de 1991, por Decreto Presidencial, o PROCEL foi transformado em programa de governo, tendo suas responsabilidades ampliadas, articulando-se com todos os segmentos da sociedade direta ou indiretamente ligados ao uso e produção de energia elétrica. Para a sua implementação, foram criados o Grupo Coordenador de Conservação de Energia (GCCE), como órgão de coordenação do PROCEL, e a Secretaria Executiva (SE) do GCCE, subordinada da ELETROBRÁS como órgão Executivo (MARTINS et al., 1999).

No período de 1985 até 1989, considerada a primeira fase da estrutura organizacional e operacional do PROCEL, observaram-se questões como a preocupação com a pesquisa e desenvolvimento tecnológico, promoção de assistência tecnológica ao segmento industrial, disposição em promover e fomentar a pesquisa de comportamento do mercado consumidor e promoção da conservação de energia elétrica pela normalização, padronização e certificação de equipamentos empregados no uso final.

A criação do Programa Nacional de Racionalização da Produção e Uso de Energia (PROENERGIA) e a instituição do Departamento Nacional de Desenvolvimento Energético levaram à mudança de enfoque do PROCEL, à medida que sua característica de programa setorialista passou a ser contrabalanceada pela sua integração em uma política ampla de conservação de energia, baseada nas diretrizes do PROENERGIA (MARTINS et al., 1999).

Verde (2000) destaca que o PROCEL passou por três fases distintas, considerando a primeira como a mais ativa e que perdurou até 1991. O programa foi direcionado na orientação da sociedade em ações de conservação de energia, levantamento de dados e estudos sobre o uso de energia pelos consumidores finais e montagem e aparelhamento laboratorial, visando ao desenvolvimento das primeiras pesquisas na busca de melhoria dos índices de eficiência dos equipamentos elétricos utilizados no Brasil.

Na segunda fase (entre 1991 e 1993), o PROCEL tornou-se programa do governo federal. Entretanto as reformas administrativas que ocorriam no Governo Collor travaram os programas em andamento, além disso, houve intensos processos de controle da saída de recursos das Centrais Elétricas Brasileira (ELETROBRÁS), principal provedora dos projetos. Nesse momento surgiram os 
Programas de Conservação de Energia nas Concessionárias (PROCECON's), produtos de convênio entre a ELETROBRÁS e as concessionárias (VERDE, 2000).

$\mathrm{Na}$ terceira fase, o PROCEL foi reestruturado com enfoque na incorporação de ações de eficiência energética no sistema elétrico. Destaca-se a redução de perdas dos sistemas de geração, transmissão e distribuição de energia elétrica, e, sobretudo, na definição objetiva dos potenciais e prioridades de conservação de energia elétrica em curto prazo, com a finalidade de alavancar os objetivos de longo prazo do programa. Projetos que possibilitassem a redução das perdas do sistema foram suportados e incentivados. Firmaram-se acordos de cooperação com entidades internacionais na Europa e América do Norte (VERDE, 2000).

Os esforços do PROCEL durante a crise de abastecimento de energia no ano de 2001 concentraram-se em buscar aliados na economia de energia. Parte dos resultados positivos se deve aos acordos com fabricantes de motores elétricos, equipamentos eletrodomésticos e de iluminação. $\mathrm{A}$ partir das mudanças estruturais do setor elétrico e com o novo marco regulatório, o país passou a priorizar a implantação ordenada de projetos de conservação de energia elétrica por parte de um grupo de empresas concessionárias e distribuidoras (VERDE, 2000).

O PROCEL vem instituindo outros programas como o Prêmio Nacional de Conservação e Uso Racional de Energia, o Selo PROCEL; O PROCEL-EDUCAÇÃO; O PROCEL NA INDÚSTRIA,; O PROCEL - EDIFICA, PROCEL nos Prédios Públicos e PROCEL SANEAR (PROCEL, 2011).

\section{O PROENERGIA e o Grupo Executivo de Racionalização Energética (GERE)}

Segundo Martins et Al (1999), o PROENERGIA foi criado pelo Decreto no 99.250, 11/05/1990 para coordenar a ação governamental em conservação de energia, por intermédio do GERE. No intuito de ampliar o escopo do PROCEL, tencionava atuar sobre todas as formas de energia ao lado da demanda e da oferta, abrangendo o setor público e a iniciativa privada, articulando-se com programas setoriais similares. Dentre as suas prioridades incluíram-se: a identificação de áreas críticas e de medidas de economia energética, promoção de ganhos de eficiência por avanço tecnológico e de produtos com maior valor agregado.

Foram realizados estudos para a proposição de normas e padrões de eficiência energética e criação de legislação, programas de fomento e linhas de crédito. Reuniram-se nove profissionais de 64 instituições participantes, destacando-se a racionalização do uso de energia em órgãos públicos, a comercialização de lâmpadas incandescentes eficientes e legislação normativa sobre índices de eficiência energética para novas edificações. O principal resultado pela atuação do GERE foi a colocação no mercado nacional das lâmpadas incandescentes - 10\% mais econômicas. Em setembro de 1992, o programa mudou de orientação, com sua passagem para a esfera do MME, que definiu novas linhas estratégicas.

\section{Principais Marcos Legais Institucionais}

Diante do cenário de crescimento projetado pelo governo brasileiro e da insuficiência de disponibilidade de energia, busca-se priorizar um modelo energético capaz de garantir o suprimento compatível com as necessidades da economia a custo mínimo e respeitando-se as restrições sociais e ambientais. (HADDAD, 2002). Dentre os principais marcos legais institucionais destacam-se:

- Lei no 9.478, 06/08/1997, instituiu o Conselho Nacional de Política Energética (CNPE). O artigo $1^{\circ}$ Inciso IV estabelece que um dos princípios e objetivos da Política Energética Nacional é "proteger o meio ambiente e promover a conservação de energia".

- Decreto no 2.335, 06/10/1997, dispõe como competência da ANEEL "incentivar o combate ao desperdício de energia no que diz respeito a todas as formas de produção, transmissão, distribuição, comercialização e uso da energia";

- Resolução no 271,19/07/2000, a ANEEL estabeleceu os critérios de aplicação de recursos em ações de combate ao desperdício de energia elétrica e pesquisa e desenvolvimento tecnológico do setor elétrico brasileiro;

- Lei oㅜ 9.991, 24/07/2000, dispõe sobre a realização de investimentos em pesquisa e desenvolvimento em eficiência energética por parte das empresas concessionárias, permissionárias e autorizadas do setor de energia elétrica;

- Lei no 10.295, 17/10/2001, trata do estabelecimento dos níveis máximos de consumo específico de energia, ou mínimos de eficiência energética de máquinas e aparelhos consumidores de energia fabricados e .

- Lei no 10.847, 15/03/2004, autorizou a criação da Empresa de Pesquisa Energética; 
- Lei $n^{\circ} 12.212,20 / 01 / 2010$, alterou por meio do seu artigo $11^{\circ}$, o artigo $1^{\circ}$ da Lei $n^{\circ}$ 9.991/2000, inciso V, que passou a vigorar com a redação "as concessionárias e permissionárias de distribuição de energia elétrica deverão aplicar, no mínimo 60\% (sessenta por cento) dos recursos dos seus programas de eficiência para unidades consumidoras beneficiadas pela Tarifa Social".

\section{Regulamentação de Edificações}

O Decreto $n^{\circ} 4.059,19 / 12 / 2001$ instituiu condições para a Etiquetagem Voluntária do nível de eficiência energética de edifícios comerciais, de serviços e públicos. Os quesitos avaliados compreendem os sistemas de iluminação, condicionamento de ar e envoltória (SOARES, 2010). Em 22 de novembro de 2010, foi divulgado que a ação de etiquetagem em edificações se estendeu às construções residenciais. Estimativas do PBE indicam que "a economia de energia nos edifícios que adotarem produtos etiquetados pode variar entre $30 \%$ e $50 \%$ " e que as edificações etiquetadas "respondem por $22,1 \%$ de toda a energia consumida no país, de acordo com o Ministério de Minas e Energia" (ABEE, 2011).

\section{Considerações gerais sobre a conservação e eficiência energética no Brasil}

Atualmente são estabelecidas metas de redução e de conservação de energia que, segundo o PROCEL (2011), são consideradas no planejamento do setor elétrico. Cabe destacar a redução nas perdas técnicas das concessionárias, racionalização do uso da energia elétrica e o aumento da eficiência energética em aparelhos elétricos.

O PROCEL economizou, até o ano de 2009, 38 mil GWh de energia. Desde sua criação foram investidos mais de um bilhão de reais que retornaram na forma de investimentos postergados em expansão do sistema elétrico. O último ciclo avaliado mostrou que em 2009 foram economizados 5,47 bilhões de $\mathrm{kWh}$, o equivalente a $1,41 \%$ do consumo total de energia elétrica fornecida durante um ano por 3 milhões de residências brasileiras. Tais resultados estão relacionados ao aumento da venda de equipamentos eficientes e a melhoria nas tecnologias estimuladas pelos programas do PROCEL (MATRIZ LIMPA, 2011).

\begin{tabular}{|l|l|}
\hline Energia Economizada (milhões de kWh) & 5.473 \\
\hline Redução de Demanda na Ponta (MW) & 2.098 \\
\hline Usina Equivalente (MW) & 1.312 \\
\hline Emissão de $\mathrm{CO}^{2}$ Equivalente Evitada (mil tCO $\left.\mathrm{CO}_{2} \mathrm{e}\right)$ & 135 \\
\hline
\end{tabular}

Quadro 1: Principais Resultados Energéticos Das Ações do Procel em 2009

Fonte: Matriz Limpa (2011)

No Plano Nacional de Energia 2030 (EPE, 2007), o valor total do montante de energia elétrica previsto a ser conservado até o ano de 2015, considerando-se que se efetivem ações e políticas com esse objetivo, corresponde a um consumo de $56.303 \mathrm{GWh}$, o que, em termos de carga de energia que deixará de ser requerida das fontes de geração, equivale a aproximadamente $7.200 \mathrm{MW}$ médios anuais.

\section{Considerações Finais}

Um cenário promissor em eficiência energética está vinculado ao estabelecimento de políticas públicas que destaquem prioridades, metas e planos de ação bem delineados; Um ponto sensível envolve a educação para o desenvolvimento de uma consciência coletiva na preservação do meio ambiente.

Como resultado das políticas abordadas neste trabalho, nota-se que o país tem avançado rumo a ações efetivas em conservação e eficiência energética, mas há de se considerar as necessidades de uma economia com projeção de crescimento entre 4\% e 5\% ao ano até 2020 (Banco Itaú, 2011) com gargalos existentes na infra-estrutura, e a responsabilidade por sediar dois grandes eventos de projeção mundial como a Copa do Mundo em 2014 e os Jogos Olímpicos de 2016. Tais eventos implicam num tradeoff entre crescimento e gestão de recursos naturais.

Os objetivos de crescimento demandam investimentos na construção de grandes empreendimentos (exemplo, Usina Hidrelétrica de Belo Monte), mas deverão responder de forma eficaz às pressões ambientais, que se agravam sugerindo que o país precisará adotar metas de redução de emissões de $\mathrm{CO}_{2}$. 
O estudo indica ainda que os órgãos competentes devem ampliar as ações de educação, pesquisa e desenvolvimento de novas tecnologias e parcerias com o setor público e privado. Adicionalmente entende-se a importância de uma contínua revisão do marco regulatório do setor elétrico, privilegiando-se as proposições em ações de eficiência energética nos diversos setores da economia.

\section{Referências}

ABEE - ASSOCIAÇÃO BRASILEIRA DE EFICIÊNCIA ENERGÉTICA. Edifícios residenciais terão selo de eficiência energética. Disponível em: <http://www.abee.org.br/index.php/novidades/59edificios-residenciais-terao-selo-de-eficiencia-energetica> Acesso em: 23 Jul. 2011.

AGENCE DE L'ENVIRONNEMEN ET DE LA MAITRISE DE L'ENER - ADEME - AGÊNCIA DO MEIO AMBIENTE E DA MATRIZ ENERGÉTICA. Disponível em: < http://www.ademe.fr > Acesso em: 11 set. 2006.

ANEEL -. AGÊNCIA NACIONAL DE ENERGIA ELÉTRICA - Disponível em: <http://www.aneel.gov.br $>$ Acesso em: 13 out. 2006.

BANCO ITAÚ. Itaú Unibanco projeta crescimento da economia brasileira entre $4 \%$ e $5 \%$ ao ano até 2020. Disponível em:

<http://colunistas.ig.com.br/guilhermebarros/2011/05/08> Acesso em: 23 Jul 2011.

CLIMATE CHANGE. Disponível em: <http://www.epa.gov/climatechage> Acesso em: 11 set. 2006.

DEFRA - DEPARTMENT FOR ENVIRONMENT FOOD AND RURAL AFFAIRS . Disponível em: <http://www.defra.gov.uk> Acesso em: 10 set. 2006.

EER - ENERGY EFFICIENCY AND RENEWABLE ENERGY. Disponível em: <Www.eere.energy.gov>. Acesso em: 18 fev. 2007.

ELETROBRÁS - CENTRAIS ELÉTRICAS BRASILEIRAS S.A. A Eletrobrás e a história do setor de energia elétrica no Brasil. Rio de Janeiro, Centro de Memória da Eletricidade no Brasil, 1995.

EPE - EMPRESA DE PESQUISA ENERGÉTICA. Plano nacional de energia 2030. Eficiência Energética: um desafio estratégico para o MME. Disponível em: <www.epe.gov.br > Acesso em: 18 fev. 2007.

GUERREIRO, Amílcar. Notas do seminário tecnologias energéticas do futuro: novas perspectivas energéticas, eficiência energética e regulação. Curitiba, 2006.

HADDAD, Jamil. Eficiência e conservação de energia. Dossiê Energia Positiva para o Brasil. Disponível em: <www.greenpeace.org.br> Acesso em: 10 set. 2006.

HADDAD, Jamil. Uso eficiente da energia: dos incentives regulatórios recentes até a atual lei de eficiência energética. Revista Brasileira de Energia. v.9, p.107-118, 2002.

IDAE - INSTITUTO PARA LA DIVERSIFICACION Y AHORRO DE LA ENERGIA. Disponível em: <http://www.idade.es> Acesso em: 10 set. 2006.

MARTINS, André Ramon Silva et. al. [organizadores: Jamil Haddad, Sérgio Catão Aguiar. Eficiência energética: integrando usos e reduzindo desperdícios. Brasília: Agência Nacional de Energia Elétrica - ANEEL; Agência Nacional do Petróleo - ANP, 1999.

MATRIZ LIMPA, Portal Ambiente Energia. Resultados e realizações do PROCEL em 2009. Disponível em: <http://www.matrizlimpa.com.br> Acesso em: 23 Jul 2011.

MINISTÉRIO DA CIÊNCIA E TECNOLOGIA. Decreto no 3.818, de 15.05.2001. Disponível em: <http://ftp.mct.gov.br/legis/decretos> Acesso em: 07 mai. 2007. 
PICCINNI, Mauricio Serrão. Conservação de energia nas indústrias: as políticas adotadas na época da crise energética. Revista do BNDS, Rio de Janeiro v.1 N.2,P. 153-182, 1994.

PROCEL - PROGRAMA NACIONAL DE CONSERVAÇÃO DE ENERGIA. Disponível em: <http://www.eletrobras.com.br> Acesso em: 21 jul. 2011.

SOARES, George Alves. Estratégias políticas para eficiência energética em edificações no Brasil. Disponível em: <www.ahk.org.br> Acesso em: 20 jul. 2011.

STRAPASSON, Alexandre Bertinardi. A energia térmica e o paradoxo da eficiência energética: desafios para um novo modelo de planejamento energético. São Paulo, 2004. Dissertação (Mestrado) Universidade de São Paulo, Programa Internunidades de Pós Graduação em Engenharia.

VERDE, Victor de Souza Villa. A conservação de energia elétrica no novo modelo institucional do setor elétrico brasileiro. Rio de Janeiro, 2000. Dissertação (Mestrado em Ciências: Planejamento Energético), Universidade Federal do Rio de Janeiro. 